\title{
Illicit Drug Markets and Economic Irregularities
}

\author{
Jonathan P. Caulkins*,** \\ Peter Reuter***,** \\ June, 2004
}

Corresponding Author: Caulkins

*H. John Heinz III School of Public Policy and Management Carnegie Mellon University

Pittsburgh, PA 15232

(412) 2689590

(412) 2685338 (FAX)

Caulkins@cmu.edu

**RAND Drug Policy Research Center

Santa Monica, CA 90407

***School of Public Policy and Department of Criminology

University of Maryland

College Park, MD 20742 


\title{
Illicit Drug Markets and Economic Irregularities
}

\begin{abstract}
:
Markets for illicit drugs present an interesting case study for economics, combining non-standard characteristics such as addiction and product illegality. One response has been to argue the generality of economic principles by suggesting that they apply even in the extreme case of markets for addictive substances, e.g., by showing that demand for illicit goods is responsive to price [1] and even by modeling addiction as rational [2]. This paper sketches examples of an alternative reaction, focusing on idiosyncrasies of drug markets that might plausibly create counter-intuitive effects, including supply curves that slope downward because of enforcement swamping and/or a good serving as the only available store of wealth for its producer, demand reduction programs that increase demand, and consumption by “jugglers” possibly increasing rather than decreasing as prices rise. This analysis yields non-obvious policy recommendations; for example, source country control programs should concentrate on growing regions with a healthy banking sector.
\end{abstract}

Keywords: Drug policy, illicit markets, market models, industrial organization

\section{Introduction}

Illicit drugs are produced, distributed, and retailed through markets, but those markets can differ in important respects from conventional markets. A literature has emerged describing various oddities of drug markets. Motivated by the observation that prices have declined despite very substantial increases in enforcement stringency (and in some cases to provide arguments for the legalization debate), an important subset of this literature is models suggesting that enforcement can stimulate rather than suppress drug supply and/or drug-related crime and violence [3-12]. 
This paper sketches four other oddities that appear plausible, although data presently available do not allow for model validation. It is not clear whether they are important drivers of overall drug market behavior. Nevertheless, they illustrate the richness of possible behaviors of markets for illicit drugs and the value of being open to models built up from special properties of those markets, rather than merely importing standard analysis and conclusions. An implication is that industrial organization economists may find drug markets to be an intrinsically interesting domain.

To clarify, by oddity we mean behavior contrary to that predicted by application of the standard competitive model to markets for illegal drugs, which has become common enough to be featured in introductory economics texts. The conventional story is comparative static analysis of a market with an upward sloping supply curve and a downward sloping demand curve. Tougher enforcement against sellers is depicted as restricting supply. The supply curve shifts up and to the left, increasing the market price and reducing the quantity of drugs sold in the market. Demand-control interventions (prevention and treatment) are described as shifting the demand curve back, leading to lower prices and quantities sold. The magnitude of the various changes is acknowledged to depend on the elasticity of demand or supply, but their sign or direction is not questioned except that the extreme case of perfectly inelastic demand is sometimes considered on the ground that drugs are "addictive”. This simple, conventional analytic framework is found not only in textbooks, but also in more august publications such as those of the National Research Council [13].

There are some virtues of even this mechanical application of elementary economic theory. Not so many years ago interdiction was viewed in policy debates within a "physical flow model” that presumed seizing a kilogram reduced consumption by a kilogram. Relative to that baseline, even elementary market models are an improvement because they acknowledge dynamic market response and notions of equilibrium. Our central thesis, however, is that economic analysis of drug markets and drug control interventions should not be content with 
presuming that elementary market models apply in all cases. In some instances the structure of the conventional model may be incorrectly specified; in others parameter values may be so different from those expected as to produce counter-intuitive results.

Before proceeding we mention four important characteristics of contemporary US cocaine and heroin markets that are not universally appreciated. For a full discussion, see [14]. First, sellers face high risks of arrest and imprisonment, as well as seizure of assets and drugs. They also face substantial risk of injury or death as a result of actions by other participants. For example, Reuter et al. [15] estimated that in 1988 a Washington, D.C. retail dealer had a one in three annual risk of arrest and a one in fourteen annual risk of serious injury. Second, the drug distribution "system" has many layers; street sellers are far removed from importers, let alone the farmers who raise the crops from which the drugs are produced. Third, in the U.S. most cocaine and heroin is consumed by persons who are dependent on these drugs, and buying these drugs absorbs a significant share of their disposable income. Fourth, a large share of those who sell cocaine and heroin are themselves heavy users of those drugs; sellers account for a substantial fraction of total consumption.

\section{Treatment that Increases the Demand for Drugs}

Normally one thinks of drug treatment as a "demand control” program that shifts the demand curve back. The exceptions, such as an ineffective program that "label” participants as heavy users thereby indirectly encouraging their use, are clearly programmatic failures. There are immunotherapies under development, however, that could increase not reduce market demand even if they are succeed at the individual level. Indeed, in some respects these therapies may be best thought of as akin to interdiction, albeit interdicting the drugs between the user's skin and brain, not between the source country and US borders.

Traditional pharmacotherapies are agonists or antagonists that interfere with a drug's binding to receptors in the user's brain. Antibodies created by immunotherapy, whether from 
active vaccination or monoclonal antibodies, are too large to cross the blood-brain barrier. Instead they bind with the drug molecule in the blood stream, preventing bound molecules of the drug from reaching the brain. Indeed, a central part of the appeal of these medications is that they may be inherently safer and have fewer side-effects precisely because they do not affect the patient's brain.

The pharmacokinetics of immunotherapies are complex and imperfectly understood, but it would seem that a consequence is that ingesting a given amount of the illicit drug produces a “smaller” psychic effect since less reaches the user’s brain. Conversely, users would have to spend more to achieve the "same" effect.

“Smaller” and "same” are in quotes because the drug experience is multi-attribute, and immunotherapies may affect different attributes to different extents. For example, they may alter the shape as well as the scale of the time-varying concentration of the drug in the brain (reducing the intensity of the "spike" by a greater or lesser percentage than they do the "area under the curve” and/or affecting the rate of increase more or less than the peak level). There may be differential effects across organs as well. (Some patients who try cocaine after being vaccinated describe not getting the rush but still experiencing similar effects on their heart. Tom Kosten, personal communication, April 24, 2003)

It is also not clear how immunotherapy affects “craving” and withdrawal. Pentel [16] argues that "immunization would not generally be expected to directly block withdrawal or craving since those occur when the drug is no longer present - although immunotherapy could slow drug elimination, possibly reducing craving.” Kleiman [17] argues that they could reduce craving because knowing a substance is not “available” can reduce craving. MacCoun [18] suggests immunotherapy-induced "extinction" of the conditioned response to drug cues may not eliminate craving, at least not reliably and quickly. The effects may vary over time because 
antibody loads vary with time after treatment. ${ }^{1}$ Hence, although we are arguing that immunotherapies can be thought of, in part, as altering the effective price to the user, we are not claiming that they may not also simultaneously affect the demand or desire for the intoxicants.

Inasmuch as immunotherapies alter the effective price for a given user after vs. before treatment, they create a wedge between price as perceived by the user and the price offered by the seller. In particular, for any given price per pure gram available from the drug dealer, the user would have to pay more to get the "same" amount of the drug into their brain. So one would expect the ultimate impact on the market price and quantity to depend in part on the users' price elasticity of demand. In particular, if the individual's elasticity of demand were low enough, the net effect could be a reduction in the quantity reaching the brain, but an increase in the quantity purchased. So at the individual user level, it is as if the supply curve shifted up, but at the aggregate market level, this treatment could actually shift out demand.

The closest analogy already analyzed in the drug field could be the effect of border interdiction on demand for drugs from the source country, such as Colombia. Interdiction raises the retail price, which reduces domestic consumption, but it also increases the amount exported from the source country per unit consumed in the US. Under plausible conditions the latter effect dominates [19], so interdiction at the border might increase, not reduce, export demand for the drug.

If immunotherapies likewise reduced the amount of a drug reaching users’ brains but increased demand from drug dealers this could have ambiguous welfare effects because some harms are driven by the extent of drug use (both the number who use and the intensity of average use) and others by the size of drug markets [20]. E.g., it is common to divide drug-related crime into three categories [21]: psychopharmacological crime (that driven directly by drug intoxication

\footnotetext{
${ }^{1}$ Antibody loads have a half-life of a month or two, even for active vaccination, and do not increase in response to subsequent exposure to the drug itself, which is too small to elicit an immune response by itself. The original response is triggered by injecting the drug bound to a carrier protein, and it is only this
} 
or withdrawal), economic-compulsive crime (crime committed by users to get money to buy drugs), and systemic crime (conflict related to drug transactions, e.g., disputes among dealers over drug money or territories). For cocaine in the US, these three components seem to account roughly for about $1 / 6,1 / 3$, and $1 / 2$ of drug-related crime, respectively [22]. The precise proportions vary over time and across geography, but psychopharmacological effects are not generally thought to dominate [23], and only psychopharmacological crime is driven directly by drug use. The latter two categories are more directly related to drug market spending and revenues, so if immunotherapies reduced the amount of the drug reaching the brain but increased market demand, they could yield a net increase in drug-related crime [17].

Indeed, even effects on health harms related to use could be ambiguous because one must differentiate among use-driven harms related to the drug's reaching the brain (e.g., many behavioral effects), its reaching other body parts (e.g., the heart or placenta), and those associated with ingestion itself. Psychopharmacological crime is presumably driven by the drug's effect on the brain. Overdose sometimes is (opiates suppressing respiratory activity via effects on the brain), but not always (toxic effects of cocaine on the heart). At present it is simply not well understood (at least by the authors), whether immunotherapies protect other body parts as well as the brain, better, or less well; the answer may be immunotherapy-, organ-, and/or drug-specific.

What is more clear is that some harms stem from the ingestion process itself, and those would be exacerbated if users sought to override immunotherapies' partial blocking of the drug. Two obvious examples are the spread of infectious diseases such as HIV and HCV via shared injection equipment and the risk of lung cancer from cigarette smoke. (The nicotine vaccine intercepts nicotine in the bloodstream, not tars and other carcinogens in the esophagus.)

Perverse scenarios are not necessarily the most likely outcome. Despite past misconceptions, drug use seems to be responsive to price and may well even be demand elastic in 
the long run. On the other hand, the duration of action from a single round of immunotherapy is a few months, not a lifetime. So if retention in immunotherapy-based treatment is as low as it has been in other forms of treatment [18], immunotherapy might look to the user like a short-term price spike, not a long term increase in equilibrium prices. There is some evidence that for addictive substances the short run elasticity of demand can be less, in absolute value, than the long-run elasticity [24] and concerns have been expressed that kinked demand curves with asymmetric responses to price increases and declines could make price variability undesirable [25] even if the long-run demand is elastic.

Much remains uncertain, including how well these immunotherapies will work in practice. Still, it seems quite plausible that the impact on market-related externalities relative to the impact on consequences related to the amount reaching the user's brain could be less favorable for immunotherapy than for other forms of treatment, and it is even plausible that this treatment could increase, rather than reduce, demand.

\section{Price Declines Reducing Consumption for “Jugglers"}

Retail or street selling of heroin, and also other of expensive illicit drugs, is often performed by “jugglers”. "Jugglers” are addicts who finance their habit by selling to other users, typically on consignment. Those other users may or may not be addicted but they finance their consumption by other means (legitimate earnings, theft, prostitution, etc.). Details of the financial arrangement vary, but among twenty-four “independent” consignment sellers studied the average proportion of retail revenues retained by the consignment seller was $25 \%$. E.g., it is common for heroin jugglers to receive a "bundle” of ten "dime-bags" of heroin on consignment for $\$ 70$, to sell seven or eight of the bags for $\$ 10$ each (dime $=\$ 10$ in street argot), and use the other two or three bags themselves [26].

There is some evidence suggesting that at these lower distribution levels, the relationship between prices at different market levels may be "multiplicative” not “additive” [25, 27-29]. 
That is, as prices vary, the retail price may remain a given multiple of the wholesale price, rather than having the difference between retail and wholesale prices remain constant. Various explanations have been offered for this, including that some important distribution costs depend more on the value rather than the weight of what is being distributed (e.g., because agents incentives to cheat or defect depend on the value rather than the weight of drugs in their possession) [28] and that sellers may think of price setting in terms of investments that must yield a certain markup rather than as covering clearly defined distribution costs [25].

Another contributing factor may be conventional pricing. Because of the importance of completing transactions quickly and surreptitiously, transaction amounts are almost always in round dollar amounts such as $\$ 10$ or $\$ 20$, but not $\$ 14.97$. Hence, prices are adjusted by varying the quantity sold, not the selling price. (Because diluents and adulterants are so very cheap compared to the price of the drug itself, this is best thought of in terms of pure grams of heroin, not the total weight of all substances, in the bag.) So, before or after a price change, the juggler can still obtain a $30 \%$ quantity discount by buying the "bundle" of 10 dime-bags for $\$ 70$. Hence, the retail price in this example is always $\left({ }^{10} / 7\right)$ times the wholesale price, even as the wholesale and retail prices vary. ${ }^{2}$

In these circumstances, drug price declines can plausibly lead to reduced rather than increased consumption by jugglers. More complicated models are possible, but a very simple one serves to make the point. Assume the juggler is a price taker at the wholesale level. Let $\mathrm{P}=$ wholesale price, and $\mathrm{k}$ = ratio of retail to wholesale prices. Suppose demand of customers supplied by the juggler has a constant price elasticity of $\eta$, so the juggler’s net revenues are c (k $P)^{\eta} k P-c(k P)^{\eta} P=c P^{\eta+1} k^{\eta}(k-1)$. Suppose for simplicity the juggler has no other source of

\footnotetext{
${ }^{2}$ Particularly for heroin outside major market cities such as New York, and to a lesser extent for powder cocaine, dealers sometimes dilute drugs. In the modern era of high potency drugs, however, that is less common. With drugs 60\% pure at retail, it is not possible that any dealer diluted the drugs 1:1 since drugs are not more than $90 \%$ pure at import. At most there was a single 1:2 cut somewhere in the five or six distribution layers between import and retail. There is evidence that this cutting does not always happen at
} 
income and spends all income on either heroin (purchased at the wholesale price) or a market basket of all other goods, denoted "food" for ease of exposition. (I.e., there is no saving, so present consumption equals present net revenue.)

The juggler's problem is to distribute consumption across food $(\mathrm{F})$ and heroin $(\mathrm{H})$ in order to maximize utility $\mathrm{U}(\mathrm{F}, \mathrm{H})$ subject to the budget constraint $\mathrm{F}+\mathrm{H} \mathrm{P}=\mathrm{c} \mathrm{P}^{\eta+1} \mathrm{k}^{\eta}(\mathrm{k}-1)$. With a Cobb-Douglas utility function, the juggler's elasticity of demand is $\eta$, the same as that of his/her customers. However, if food is thought of as necessity requiring some minimum level of spending (M) to survive, then utility might better be modeled by a Stone-Geary utility function $\mathrm{U}(\mathrm{F}, \mathrm{H})=(\mathrm{F}-\mathrm{M})^{\alpha} \mathrm{H}^{\beta}$. In that case, the utility maximizing amount of heroin consumption is

$$
H^{*}(P)=\frac{\beta}{\alpha+\beta}\left(c P^{\eta} k^{\eta}(k-1)-\frac{M}{P}\right),
$$

and the smuggler's elasticity of demand is

$$
\frac{d H^{*}(P)}{d P} \frac{P}{H^{*}}=\frac{c P^{\eta+1} k^{\eta}(k-1) \eta+M}{c P^{\eta+1} k^{\eta}(k-1)-M}=\frac{\eta+f}{1-f},
$$

where $\mathrm{f}=$ the minimum required spending on food, expressed as a fraction of the juggler's revenues from drug sales.

So, if demand from regular customers is relatively elastic, then demand from jugglers is still more elastic. Conversely, if demand from regular customers is relatively inelastic $(\eta>-1)$, then demand from jugglers is still less elastic. In particular, if the absolute value of the elasticity of demand from regular customers is less than the fraction of drug revenues a juggler must spend on “food” (i.e., food and other necessities), then the jugglers' elasticity of demand is positive, and the jugglers' heroin consumption increases when heroin prices rise.

This is akin to the classic example of an apple farmer consuming fewer apples when apple prices decline. A key difference, however, is that apple farmers presumably account for a 
very small fraction of national apple demand. E.g., the U.S. Apple Association website (www.usapple.org/industry/membership/index.shtml) reports that there are about 7,500 apple growers, or about $0.01 \%$ of the US population assuming each grower represents a family of four. In contrast, heroin jugglers are thought to comprise a substantial fraction of total heroin demand. Call that fraction $\theta$. Then the overall market elasticity of demand is

$$
\theta \frac{\eta+f}{1-f}+(1-\theta) \eta=\eta+\frac{\theta f(1+\eta)}{1-f}
$$

Depending on one’s beliefs concerning the three relevant parameters ( $\eta, \theta$, and $f)$, this expression could be noticeably different than that of the customers' elasticity ( $\eta$ ).

\section{Downward Sloping Supply for Afghan Opium}

Just as the fact that jugglers both use and sell heroin can lead their consumption to decline as price falls, so too in the short run can one have producers offer less of a good when price rises if that good is simultaneously a store of value, as is the case for opium in some underdeveloped source countries, notably Afghanistan [31]. Many conventional economic institutions in Afghanistan are simply non-functional. In particular, many peasants do not have access to banking services, either to borrow or to make deposits; non-bank credit is very expensive. As a result, holding opium, which is relatively compact and non-perishable, is a common way to save from growing season to growing season. In good times, opium farmers may hold back some of a year's production from the market to save for a rainy day (or, more accurately, a year of drought).

In this circumstance, at the end of the growing season a farmer with no other source of income faces a problem that is similar to that of the heroin juggler in the previous section. In particular, the farmer's utility is a function of present consumption (financed entirely by current opium sales since there is no borrowing) and future consumption (financed in part by the future sale of opium that is available now but that is withheld from the market, as well as by the 
proceeds of future harvests). The question is, if the current price of opium rose, should the farmer offer more or less of the current harvest for sale? Higher prices allow opium to be converted into consumption goods at a favorable rate now, so the farmer could either consume the same amount while saving more or consume more while saving the same amount or some combination. What is preferred depends on the utility function.

To formalize this, let $\mathrm{k}=$ the amount of opium on hand, $\mathrm{P}=$ the current market price of opium, and $\mathrm{Q}=$ the amount sold. So $\mathrm{k}-\mathrm{Q}$ is saved until the next year. If we defined a future price of opium, this quantity of saved opium could be translated into future consumption, but doing so needlessly adds an additional parameter (future price); it is simpler just to view the choice as between current consumption and savings, rather than the equivalent choice of current consumption and future increment to consumption over and above that which can be financed by next year's income. Likewise, for simplicity and without loss of generality assume that the price of the market basket of current consumption goods (call it “food” for short) is $\$ 1$.

If the farmer sold all of the current crop, s/he could consume $\mathrm{k}$ P now. If the farmer saved everything, the amount saved would obviously be k. All linear combinations of those extreme points are possible. Viewed on savings-consumption axes, when opium prices decline, the farmer's options are reduced unless s/he were saving everything. Depending on the indifference curves, opium price declines may or may not reduce the quantity of opium the farmer brings to market. (See Figure 1.)

Formally the farmer's problem is to distribute the current opium crop between sales (Q) to support current consumption of food (F) and savings of opium (S) in the manner that maximizes utility $\mathrm{U}(\mathrm{F}, \mathrm{S})$ subject to the budget constraint $\mathrm{Q}+\mathrm{S}=\mathrm{k}$ and the "units conversion” $\mathrm{F}$ $=\mathrm{Q}$ P. With a Cobb-Douglas utility function, the quantity of opium supplied is independent of the price of opium. If food today is thought of as more of a necessity than future savings and, hence, better modeled by a Stone-Geary utility function $U(F, S)=(F-c)^{\alpha} S^{\beta}$, then the utility maximizing amount of opium provided by the farmer to the market 


$$
Q^{*}(P)=\frac{1}{\alpha+\beta}\left(\alpha k+\frac{\beta c}{P}\right)
$$

is decreasing in $\mathrm{P}$.

Figure 1 about here

This suggests an interesting policy implication, namely that, according to this model, post-planting opium supply control efforts directed at source countries with functioning banking systems may do more to raise heroin prices in consumer nations (such as the European Union) than would equivalent efforts directed at a country like Afghanistan.

To see this, suppose there are two growing regions. In one, call it Afghanistan, there is no banking system, so the schedule of Afghan opium supplied at the end of the current growing season as a function of the market price looks like Equation 4. Specifically, it is a constant plus another term that is decreasing in price, where the constant is proportional to the harvest size $\mathrm{k}$ and the second term is independent of the harvest. I.e., $\mathrm{S}_{\mathrm{A}}(\mathrm{P})=\alpha \mathrm{k}+\mathrm{f}(\mathrm{P})$ with $\mathrm{f}^{\prime}(\mathrm{P})<0$. In the second region, call it Pakistan, farmers can save or invest cash proceeds from sales, so the quantity supplied from Pakistan increases in the market price for the usual reasons. I.e., $\mathrm{S}_{\mathrm{P}}(\mathrm{P})=$ $g(P)$ with $g$ ' $(P)>0$. The aggregate supply curve is the sum of the two, and the demand curve is downward sloping. ${ }^{3}$

Suppose that in the absence of any new intervention the two regions would contribute equally to collective supply at whatever price $\mathrm{P}_{0}$ cleared the market. Now suppose a policy maker had the choice of eliminating a fraction $\phi$ of production in either country. If the policy

\footnotetext{
${ }^{3}$ The aggregate supply curve is still probably best thought of a regional rather than a global supply curve since most Southwest Asian heroin remains in the Eastern Hemisphere. The US market is now primarily supplied by Colombia and Mexico, and is not in direct price competition with Southwest Asian heroin. E.g., Western Hemispheric heroin has rapidly gained dominant market share in the US even though it is more expensive, perhaps because it has easier access to distribution channels within the US. At any rate,
} 
maker's only consideration were increasing this year's market price (in order to suppress consumption), the policy maker would prefer to conduct eradication in the country with a working capital market (Pakistan).

To see this note that eradication in either country will raise the equilibrium price. But for all $\mathrm{P}>\mathrm{P}_{0}, \mathrm{~g}(\mathrm{P})>\mathrm{g}\left(\mathrm{P}_{0}\right)=\alpha \mathrm{k}+\mathrm{f}\left(\mathrm{P}_{0}\right)>\alpha \mathrm{k}$, so $(1-\phi) \mathrm{g}(\mathrm{P})>(1-\phi) \alpha \mathrm{k}$. Letting denote supply modified to reflect eradication, this implies that $\forall P>P_{0}, \tilde{S}_{A}(P)+S_{P}(P)=\phi \alpha \mathrm{k}+\mathrm{f}(\mathrm{P})+\mathrm{g}(\mathrm{P})$ $=\alpha k+f(P)+g(P)-(1-\phi) \alpha k>\alpha k+f(P)+g(P)-(1-\phi) g(P)=\alpha k+f(P)+\phi g(P)=S_{A}(P)+$ $\widetilde{S}_{P}(P)$. Thus for all $\mathrm{P}>\mathrm{P}_{0}$, the aggregate supply curve obtained when eradicating in Afghanistan is above (larger quantity offered for any given price) the aggregate supply curve obtained when eradicating in Pakistan. Hence, this year's equilibrium market price for opium in source countries and, hence, presumably the retail price of heroin derived from this opium, will be higher, all other things being equal, if eradication focuses on growing areas with functioning capital markets.

\section{Enforcement Swamping and a Downward Sloping Supply Curve}

Typically supply curves slope upward, but it has long been recognized that industry-wide external economies of scale can work against the usual argument of diminishing returns to marginal factors of production [32]. Thus, greater quantities of production can lower rather than raise per-unit costs and, in a competitive market, generate a downward-sloping supply curve. Whether a downward sloping actually manifests depends on the relative strength of the industrywide external economies of scale and effects of diminishing returns.

In the case of illicit drug distribution, enforcement swamping [33] may be a quite powerful industry-wide economy of scale. The standard "risks and prices” model of domestic distribution [34] presumes entry and competition bid away pure rents and, hence, that in 
equilibrium total industry revenue just equals total industry cost, once compensation for the risks of enforcement and violence are recognized as genuine economic costs. (Contrary to some popular conceptions, studies have found competition not monopolistic markets at least at the local [e.g., 35] and mid-level [36] within the US.) Inasmuch as the industry-wide costs ("tax”) imposed by enforcement increase less than linearly in market volume, a downward sloping supply curve could emerge, at least over some quantity ranges.

This argument makes three assumptions. First, enforcement risk is an important part of the industry cost structure for supplying illicit drugs. That is not hard to see. Illicit drugs such as cocaine and heroin are little more than semi-refined agricultural products, yet at retail they are worth many times their weight in gold. The reason is in no small part compensation for the risks of enforcement [34].

Second, the size of the "tax" imposed by enforcement is concave in market volume. This is clearest in the case of compensation for the risk of imprisonment, which has been estimated to be about one-quarter of the cost structure for cocaine [37]. With over-crowded prisons subject to court-imposed caps, the amount of drug-related incarceration might increase only modestly if at all with an increase in total quantity sold in the market. For any fixed level of incarceration, measured, say, in prison-years allocated per calendar year, increasing the size of the market ought to reduce the risk per market participant and, hence, reduce the risk compensation “tax" per kilogram delivered.

Compensation for arrests and seizures is probably similar in spirit but less extreme. A given number of enforcement agents ought to be able to arrest more dealers and seize more drugs and assets as the market grows, simply because targets are more plentiful. However, enforcement productivity would only be linear in target size for that small portion of enforcement that looks like random search, and even Customs inspections at ports of entry has important elements that

Hemisphere accounts for even that much. 
are intelligence-driven, not just blind search. Hence, one would expect these aspects of risk compensation also to be concave in market volume.

The third assumption is that the other components of the industry cost structure do not increase much more than linearly in the quantity produced. This is plausible in the medium to long run since the relevant factors of production are not generally highly constrained. In particular, conventional distribution costs for packaging, additives, transportation, marketing, etc. are a trivial portion of the industry cost structure [37]. Besides compensation for the risks of enforcement, there appear to be three other significant costs (estimates in parentheses are for cocaine [37]): (1) costs of importing the drug into the US ( 12\% of retail value), (2) compensation for domestic sellers' time ( 13\%), and (3) compensation for risks of injury and death (33\%). The first two are unlikely to be subject to markedly diminishing returns, at least in the long run. The supply curve of labor willing to produce drugs in source countries, smuggle them into the US, and retail them here is quite flat. The per-person risk of violence might conceivably increase with market size if that increased the number of interactions among strangers who are not able to resolve disagreements in non-violent ways. However, one could equally argue that a decline in supra-competitive rewards associated with increased competitiveness might lead to reduced violence.

Although the idea that enforcement swamping might generate industry-wide external economies of scale has been incorporated in various models [22,38], it remain controversial [13], even though it turns out not to be a major driver of the best known conclusions of those models [39]. Presumably at a minimum it could be a factor that tends to flatten any upward slope in the supply curve, even if it does not make the slope actually negative.

\section{Discussion}

Illicit drug markets are indisputably markets, but the institutional details present interesting twists on the most familiar market models. Four illustrations are offered here. The 
first recognized that immunotherapy treatment for substance abuse intervenes between retail purchase and the purchaser deriving utility from that purchase. This is somewhat akin to spoilage, pilferage, or leakage creating a wedge between what is paid for and what is received. Plausibly this treatment intervention could lead to less intoxication but more demand from sellers, with ambiguous welfare effects since some drug-related harms stem from the black markets, not intoxication. The second considered consumption by heroin "jugglers" who both sell and consume heroin. Declining prices reduce their income. Under certain circumstances income effects might dominate, so heroin demand varies positively not negatively with price. The third considered opium farmers for whom opium is both a cash crop and, in the absence of a viable banking industry, the primary store of value. At the end of the harvest season, higher opium prices might allow farmers to save more, which is to say offer less to the market, another instance of a downward sloping supply curve. The fourth stemmed from sellers collectively incurring costs from an enforcement "tax" whose total magnitude increases less than linearly in industry volume. The resulting industry-wide external economies of scale could lead to a downward sloping supply curve.

Two recent papers add other examples. Taylor developed a model [40] in which heterogeneity in sellers' affinity for violence can mean that tougher enforcement reduces rather than increases prices. In that model differential proclivity for violence creates inheritable heterogeneity along a dimension that both reduces production cost (e.g., by conferring protection against enforcement) and generates an external cost borne by other sellers. Together these features generate counter-intuitive policy implications. For example the arrest of a particularly violent dealer reduces external costs borne by other dealers. The net effect is a possible reduction in costs for the marginal dealer and hence a reduction in price.

In another recent paper, Caulkins and MacCoun [41] note that it is perceived not actual risk that matters for deterrence. Furthermore, there are structural attributes of drug sellers' decisions that mirror ones in other contexts that the psychological literature has found to be prone 
to systematic and substantial errors in judgments concerning risk and uncertainty. For example, for the decision to sell drugs, the relative appeal of the "sell” and "don't sell” options can be very different depending on whether one is deciding to sell just once or for an extended period and on whether one's frame of reference (zero point) is not selling or having sold successfully. The interaction of the two could entice and "trap" people into selling on an ongoing basis even if when framed differently, the enforcement risks would have deterred the individual from selling.

There would appear to be abundant opportunities for more such modeling. For example, MacCoun [42] identified two potential anomalies in demand suppression; enforcement might exacerbate "forbidden fruit” effects and/or increase consumption among users who are increasingly stigmatized.. We do not know which of these twists are truly important. We do know that drug markets do not always behave as expected. Notably, the failure of cocaine and heroin prices to rise in the face of vastly increased enforcement intensity and fairly stable demand is something of a puzzle. Examining ways in which these markets might depart from the standard paradigm could improve our understanding of drug policy and perhaps offer an informative data point for industrial organization theorists.

\section{Acknowledgements}

We thank Robert MacCoun and Lowell Taylor for their many helpful comments on earlier drafts. This work was supported in part by a grant from the Robert Wood Johnson Foundation's Substance Abuse Policy Research Program.

\section{References}

[1] Chaloupka FJ, Pacula RL. Economics and anti-health behavior: the economic analysis of substance use and abuse. In: Bickel W, Vuchinich R, eds. Reframing Health Behavior Change with Behavioral Economics. Hillsdale, NJ: Lawrence Earlbaum Associates; 2000: 89-111

[2] Becker G, Murphy K. A Theory of Rational Addiction. J. Political Economy 1988;96:675700. 
[3] Benson BL, Rasmussen DW. “The Relationship Between Illicit Drug Enforcement Policy and Property Crimes. Contemporary Policy Issues 1991;9:106-115.

[4] Benson BL, Kim I, Rasmussen DW, Zuehlke, TW. Is Property Crime Caused by Drug Use or Drug Enforcement Policy. Applied Economics 1992;24:679-692.

[5] Caulkins JP. Zero-Tolerance Policies: Do They Inhibit or Stimulate Illicit Drug Consumption? Management Science 1993;39(4):458-476.

[6] Caulkins JP, Padman R. Interdiction's Impact on the Structure and Behavior of the ExportImport Sector for Illicit Drugs. Zeitschrift fur Operations Research 1993;37:207-224.

[7] Miron JA, Zwiebel, J. The Economic Case Against Drug Prohibition. The Journal of Economic Perspectives 1995;9(4):175-192.

[8] Miron JA. Violence and the U.S. Prohibitions of Drugs and Alcohol. American Law and Economics Review 19991:78-114.

[9] Burrus RT. Do Efforts to Reduce the Supply of Illicit Drugs Increase Turf War Violence? A Theoretical Analysis. Journal of Economics and Finance 1999;23(3):226-234.

[10] Poret S. The Illicit Drug Market: Paradoxical Effects of Law Enforcement Policies. International Review of Law and Economics 2003;22(4): 465-493.

[11] Poret S, Tejedo C. Law Enforcement and Concentration in Illicit Markets. 2002, Mimeo.

[12] Skott P, Gepsen GT. Paradoxical Effects of Drug Policy in a Model with Imperfect Competition and Switching costs. Journal of Economic Behavior and Organizations 2002;48(4) 335-354.

[13] Manski CF, Pepper JV, Petrie CV (eds.) Assessment of Two Cost-Effectiveness Studies on Cocaine Control Policy. Washington, DC: National Academy Press, 1999.

[14] Kleiman MAR. Against Excess: Drug Policy for Results. New York: Basic Books, 1992.

[15] Reuter PR, MacCoun R, Murphy P. Money From Crime: A Study of the Economics of Drug Dealing in Washington, D.C. Santa Monica: RAND, 1990.

[16] Pentel P. Vaccines and Depot Medications for Drug Addiction: Rationale, Mechanisms of Action, and Treatment Implications. In: Henrick Harwood (ed.), Behavioral, Ethical, Legal, and Social Implications of Immunotherapies and Depot Medications for Treating Drug Addiction. Washington, DC: National Academy Press, 2004.

[17] Kleiman MAR. Costs and Benefits of Immunotherapies or Depot Medications for the Treatment of Drug Abuse. In: Henrick Harwood (ed.), Behavioral, Ethical, Legal, and Social Implications of Immunotherapies and Depot Medications for Treating Drug Addiction. Washington, DC: National Academy Press, 2004.

[18] MacCoun RJ. Anticipating Unintended Consequences of Vaccine-Like Immunotherapies for Addictive Drug Use. In: Henrick Harwood (ed.), Behavioral, Ethical, Legal, and Social 
Implications of Immunotherapies and Depot Medications for Treating Drug Addiction.

Washington, DC: National Academy Press, 2004.

[19] Henry DP. The Effects of Interdiction on Drug Exports. Appendix A in Reuter P, Crawford, G, Cave J, Sealing the Borders: The Effect of Increased Military Participation in Drug

Interdiction, Santa Monica: RAND, 1988.

[20] MacCoun R, Reuter, P. Drug War Heresies New York: Cambridge University Press, 2001.

[21] Goldstein PJ. The Drugs/Violence Nexus: A Tripartite Conceptual Framework. Journal of Drug Issues 1985;15(4): 493-506.

[22] Caulkins JP, Rydell CP, Schwabe WL, Chiesa J. Mandatory Minimum Drug Sentences: Throwing Away the Key or the Taxpayers’ Money? Santa Monica: RAND, 1997.

[23] MacCoun, R., Kilmer, B. and Reuter, P. Research on Drug-Crime Linkages: The Next Generation, in Toward a Drugs and Crime Research Agenda for the $21^{\text {st }}$ Century. National Institute of Justice Special Report. Washington, DC: USGPO, September, 2003.

[24] Becker GS, Grossman M, Murphy, KM. An Empirical Analysis of Cigarette Addiction. The American Economic Review 1994;84:397-418.

[25] Boyum D. Reflections on Economic Theory and Drug Enforcement. Doctoral dissertation, Cambridge: Harvard University, 1992.

[26] Caulkins JP, Johnson B, Taylor A, Taylor L. What Drug Dealers Tell Us About Their Costs of Doing Business. Journal of Drug Issues. 1999;29(2):323-340.

[27] Caulkins JP. The Distribution and Consumption of Illicit Drugs: Some Mathematical Models and Their Policy Implications. Doctoral dissertation. Cambridge: MIT, 1990.

[28] Caulkins JP. Developing Price Series for Cocaine. Santa Monica: RAND, 1994.

[29] Crane BD, Rivolo AR, Comfort, GC. An Empirical Examination of Counterdrug Program Effectiveness. IDA Paper P-3219, Alexandria: Institute for Defense Analysis, 1997.

[30] Reuter P, Caulkins JP. In submission. Illegal Lemons: Price Dispersion in Cocaine and Heroin Markets.

[31] United Nations Office on Drugs and Crime. The opium economy in Afghanistan - an international problem. New York: United Nations, 2003.

[32] Samuelson PA. Economics, Ninth Edition. New York: McGraw-Hill Book Company, 1973.

[33] Kleiman MAR. Enforcement Swamping: a Positive-Feedback Mechanism in Rates of Illicit Activity. Mathematical and Computer Modeling 1993;17, 65-75.

[34] Reuter P, Kleiman MAR. Risks and Prices: An Economic Analysis of Drug Enforcement. In: Morris and Tonry, editors Crime and Justice: An Annual Review of Research Volume 7, 1986:289-340. 
[35] Levitt S, Venkatesh SA. An Economic Analysis of a Drug-Selling Gang's Finances. Quarterly Journal of Economics 2000;115(3):755-789.

[36] Reuter P, Haaga J. The Organization of High-Level Drug Markets: An Exploratory Study. Santa Monica: RAND, 1989.

[37] Caulkins JP, Reuter P. What price data tell us about drug markets. J. Drug Issues 1998;28(3) 593-612.

[38] Rydell CP, Caulkins JP, Everingham SS. Enforcement or Treatment? Modeling the Relative Efficacy of Alternatives for Controlling Cocaine. Operations Research 1996;44, 1-9.

[39] Caulkins JP with Chiesa J and Everingham SS. Response to the National Research Council's Assessment of RAND’s Controlling Cocaine Study. Santa Monica: RAND, 2000.

[40] Caulkins JP, Reuter, P. Taylor L.In submission. Can Supply Restrictions Lower Prices? Violence, Drug Dealing, and Positional Advantage.

[41] Caulkins JP, MacCoun R. Limited Rationality and the Limits of Supply Reduction. Journal of Drug Issues. 2003;33(2):433-464.

[42] MacCoun, R. Drugs and the Law: A psychological analysis of drug prohibition Psychological Bulletin 1993113 497-512. 
Figure 1: When Opium Prices Fall from $\mathrm{P}_{0}$ to $\mathrm{P}_{1}$, the Farmer's Opium Savings May Fall from $\mathrm{S}_{0}$ to $\mathrm{S}_{1}$. I.e., the Amount Supplied to the Market Could Rise from $\mathrm{k}-\mathrm{S}_{0}$ to $\mathrm{k}-\mathrm{S}_{1}$

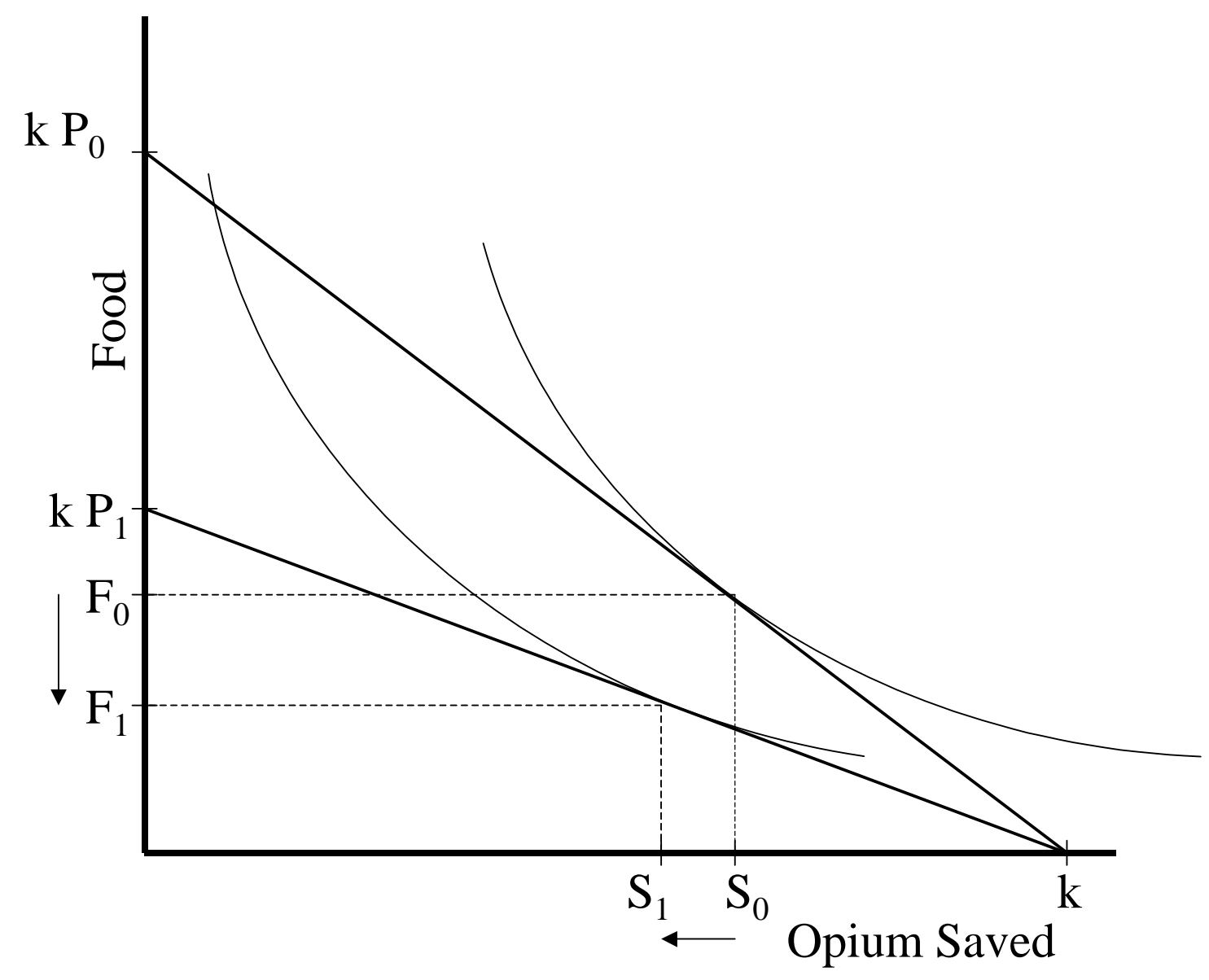

